\title{
Physicochemical, Organoleptic Evaluation and Shelf Life Extension of Quinoa Flour-Coated Chicken Nuggets
}

\author{
Sobhy A. El-Sohaimy $\mathbb{D}^{1,2}$ Miral G. Abd El-Wahab $\mathbb{D}^{2,3}$ Zilolakhon A. Oleneva, ${ }^{1}$ \\ and Abduvali D. Toshev ${ }^{1}{ }^{1}$ \\ ${ }^{1}$ Department of Technology and Organization of Public Catering, Institute of Sport,Tourism and Service, \\ South Ural State University, 454080 Chelyabinsk, Russia \\ ${ }^{2}$ Department of Food Technology, City of Scientific Research and Technological Applications (SRTA-City), \\ 21934 Alexandria, Egypt \\ ${ }^{3}$ Pharmaceutical and Fermentation Industries Development Centre, \\ City of Scientific Research and Technological Applications (SRTA-City), 21934 Alexandria, Egypt
}

Correspondence should be addressed to Sobhy A. El-Sohaimy; elsohaimys@gmail.com

Received 4 August 2021; Revised 4 November 2021; Accepted 22 December 2021; Published 31 January 2022

Academic Editor: Chunpeng Wan

Copyright (C) 2022 Sobhy A. El-Sohaimy et al. This is an open access article distributed under the Creative Commons Attribution License, which permits unrestricted use, distribution, and reproduction in any medium, provided the original work is properly cited.

\begin{abstract}
The objective of the current study was to develop innovative quinoa-coated chicken nuggets by using quinoa flour instead of wheat flour and evaluate the impact of this substitution on the shelf life of the product and its nutritional and sensorial stability. The evaluation of the product has been done through physiochemical and microbiological analysis every three days of the storage period compared with negative control (NC) and positive control (BHT) through 24 days of cold storage $\left(4 \pm 1^{\circ} \mathrm{C}\right)$. During storage, the quinoa flour-coated chicken nuggets showed the best ability for delay of lipid oxidation with a lowest TBARS value of $1.07 \mathrm{mg}$ $\mathrm{MDA} / \mathrm{kg}$ compared to negative control (NC) $(2.39 \mathrm{mg} \mathrm{MDA} / \mathrm{kg})$ and positive control (BHT) (2.00 mg MDA/kg). The same trend was observed in protein oxidation, where the quinoa flour was able to retard the protein oxidation better than negative and positive control (BHT) where it showed a carbonyl content of $6.44,5.39$, and $4.20 \mathrm{nmol}$ carbonyl content $/ \mathrm{mg}$ protein, respectively. The quinoa-coated chicken nuggets showed the lowest microbial load $\left(5.8 \times 10^{3} \mathrm{cfu} / \mathrm{g}\right)$ compared to negative and positive controls $(1.8 \times 105$ and $3.8 \times 104 \mathrm{cfu} / \mathrm{g})$ at 24 days of cold storage. These findings could be emphasized such that the utilization of quinoa flour in the coating of chicken nuggets is more effective in retarding lipid and protein oxidation, furthermore preventing microbial contamination during cold storage. All these findings might be playing a crucial role in the extending of the shelf life of the product in addition to giving the product a pleasant taste and flavor to consumers.
\end{abstract}

\section{Introduction}

Chicken meat is vital in human nutrition for its unique natural content of health-promoting compounds and nutritive value. The demand for chicken-derived products enriched with valuable nutritional components is expected to increase worldwide. These required new chicken meat products must be not only high in nutritional value but also safe, tasty, and suitable for consumption [1]. However, processed chicken meat is more susceptible to oxidative changes than raw unprocessed meat [2]. Chicken meat contains, besides valuable nutritional values, a high content of polyunsaturated fatty acids, which highly susceptible to oxidative deterioration during storage affecting its shelf life [3]. The chief ingredient of chicken nuggets is the battered and breaded part; frying of battered and breaded nuggets is used to improve their quality and organoleptic attributes such as crispness, texture, appearance, and flavor [4]. Wheat flour is the primary component usually used in the battered and breaded part of chicken nuggets. For producing a specific product suitable for celiac disease, substitution of wheat flour with amaranth flour in batter, chicken paste, and all layers of chicken nuggets at $0.50 \%$ has been developed by [5]. Recently, the poultry meat industry has been 
progressively seeking to replace the synthetic antioxidants that are currently in use with natural antioxidants that do not cause health issues and positively affect the consumer's final purchase decisions [6]. The utilization of natural preservatives in different processed meat products retarded the protein and lipid oxidation and extended their shelf life [7]. In the recent research work, there are many natural bioactive compounds that have been used for improving the quality of meat and poultry products. Carvacrol microcapsules along with seed gum reduced the primary and secondary oxidation rates of the chicken nuggets. The use of quince seed gums along with $0.5 \%$ of carvacrol microcapsules in batter coatings improved the color, texture, and sensory properties of fried nugget samples [8]. Adding of $2 \%$ tomato paste with $1 \%$ pectin to chicken sausage inhibited lipid oxidation and enhanced the organoleptic properties [9]. Using an active pretreatment of pectin and tomato paste in meat products reduced oil uptake and lipid oxidation and improved the organoleptic and texture properties of the products resulting in a healthier fastfood product after the deep-fat frying process [10]. Quinoa seeds (Chenopodium quinoa Wild.) and quinoa products are valuable sources of protein, essential amino acids, polysaccharides, vitamins, and minerals $[11,12]$. Moreover, they are rich in polyphenols including phenolic acids, flavonoids, and tannins, which contribute to its high antimicrobial, antioxidant, anti-inflammatory, antitumor, and anticarcinogenic effects $[13,14]$. Nowadays, celiac disease is a harmful immune disease affecting the human small intestine due to the disability of protein digestion that leads to malabsorption of essential nutrients such as vitamins and minerals. Such disease estimated to affect 1 in 100 people worldwide. A strictly followed gluten-free (GF) diet throughout the patient's lifetime is the only effective treatment for celiac disease [15]. Patients with celiac disease should avoid gluten in their diet with maintaining of a balanced diet. So, a gluten-free diet maintains the health intestine and reduces the celiac symptoms. On the other hand, the celiac patients are suffering from many issues connected with gluten free products such as (i) many processed foods are contaminated with gluten, (ii) staple gluten-free foods are not widely available, and (iii) the gluten free substitutes are often expensive [16]. Therefore, the present study focused on the substitution of wheat flour for battered and breaded chicken nuggets with quinoa flour to prepare health promoting gluten-free chicken nuggets suitable for people suffering from celiac disease. Furthermore, taking advantage of quinoa bioactive components in the possibility of the extension of shelf life by retarding of the lipid and protein oxidation and microbiota in the products due to the presence of antioxidants compounds that might demonstrate a potentiality as natural preservatives.

\section{Materials and Methods}

\subsection{Materials}

Quinoa seeds (Chenopodium quinoa Wild.) were collected from the experimental farm of City of Scientific Research and Technological Applications, Alexandria, Egypt, in 2019. The collected seeds were purified from foreign materials and stored in a cold room at $4 \pm 2^{\circ} \mathrm{C}$ for further use.

Chicken meat was purchased from Carrefour Alexandria market (Alexandria, Egypt) and transferred to laboratory and freezing and aseptic conditions.

Chemicals, reagents, and microbiological media were phrased from Sigma-Aldrich, USA.

The experiment has been carried out in the Department of Food Technology, City of Scientific Research and Technological Applications, Alexandria, Egypt in 2019.

\subsection{Methods}

2.2.1. Flour Preparation. Quinoa flour has been prepared by the following by the method described by [17]. To remove saponins, the seeds were washed twice with cold water, after that they were soaked in alkaline solution $(1 \%$ sodium bicarbonate) for 10-20 min and then rinsed with $1 \%$ citric acid solution for $10 \mathrm{~min}$, and then the seeds were washed with water until there was no foam that indicates saponin removal from the seeds. Later, the saponin free seeds were spread in a thin layer to avoid germination and contamination-in an airdrying oven at $45 \pm 1^{\circ} \mathrm{C}$ overnight for drying. Finally, the dried seeds were ground into flour using Miller (KARIZMAJX-1000A) and kept at $4 \pm 1^{\circ} \mathrm{C}$ for further use.

\subsubsection{A Proximate Chemical Analysis of Minced Chicken} Meat. The moisture, protein, fat, and ash content of minced chicken meat was determined by following [18] assays.

2.2.3. Preparation of Chicken Nuggets. The manufacturing of chicken nuggets was carried out in a fully equipped and sanitized laboratory in the Department of Food Technology, City of Scientific Research and Technological Applications according to Egyptian Standards [19] as shown in Table 1. The ground poultry meat was mixed until a homogenous distribution was obtained, and then it was divided into three equal portions. The first portion was coated with wheat flour without any additions (negative control, NC); the second portion was prepared with $0.02 \% \mathrm{BHT}(200 \mathrm{ppm})$ which is usually used in the manufacturing of meat products as antioxidant and wheat flour (positive control, PC). The third portion was coated with quinoa flour (QN). The poultry meat mixture of each treatment was shaped to chicken nuggets $(3.8 \mathrm{~cm}$ diameter, $1.3 \mathrm{~cm}$ thickness with average weight $17.5 \mathrm{~g}$ ). Each 3 chicken nugget pieces were placed into foam plates, wrapped with polyethylene film, and stored at $4 \pm 1^{\circ} \mathrm{C}$ for 24 days. These samples are considered as fresh chicken nuggets (not packaged).

2.2.4. Lipid Oxidation. Chicken nugget samples were evaluated for thiobarbituric acid reactive substances (TBARS) following the method described by [20]. The results were expressed as milligrams of malonaldehyde per kilogram of chicken nugget (mg MDA/Kg sample). 
TABLE 1: Recipe of manufactured chicken nugget samples.

\begin{tabular}{lccc}
\hline Ingredients \% & Control & BHT & Quinoa nuggets \\
\hline Lean poultry meat & 73.58 & 73.58 & 73.58 \\
Fat & 12 & 12 & 12 \\
Salt & 0.92 & 0.92 & 0.92 \\
Spice's mixture & 1 & 1 & 1 \\
Ice water & 7.5 & 7.5 & 7.5 \\
Fresh onion & 5 & 5 & 5 \\
BHT\% & - & 0.02 & - \\
Wheat flour coating in batter\% & 100 & 100 & - \\
Quinoa flour coating in batter\% & - & - & 100 \\
\hline
\end{tabular}

Spice's mixture was prepared from white pepper (25\%), garlic powder (25\%), ginger (15\%), thyme (15\%), red pepper (10\%), and paprika (10\%). Each type of spice was powdered before mixing. After processing nuggets are stored in batter.

2.2.5. Protein Oxidation. Protein oxidations of chicken nugget samples were quantified using the spectrophotometric DNPH assay described by Levine et al. [21]. The absorbance was measured at 280 and $370 \mathrm{~nm}$ with a UV-VIS
1800 spectrophotometer to quantify the carbonyl content. Carbonyl content, expressed as nanomoles of carbonyls per milligram of protein ( $\mathrm{nmol} / \mathrm{mg}$ of protein), is calculated according to the following equation:

$$
\text { carbonyl group content }=\frac{\text { Abs 370 s }- \text { Abs 370 b }}{2200 \times[\text { Abs 280s }-(\text { Abs 370 s }- \text { Abs 370 b) } \times 0.43]} \times 10^{6} \text {, }
$$

where Abs $370 \mathrm{~s}=$ absorbance of sample at $370 \mathrm{~nm}$, Abs 370 $\mathrm{b}=$ absorbance of blank at $370 \mathrm{~nm}$, Abs $280 \mathrm{~s}=$ absorbance of sample at $280 \mathrm{~nm}$, Blank $=800 \mu \mathrm{L}, \mathrm{HCl} 3 \mathrm{M}+1.5 \mathrm{~mL}$ Guanidine, and $\mathrm{HCl}$ in $\mathrm{NaH}_{2} \mathrm{PO}_{4}$ solution.

2.2.6. $\mathrm{pH}$ Value. $\mathrm{pH}$ values were determined according to [22]. Chicken nugget samples $(10 \mathrm{~g})$ were homogenized in $100 \mathrm{~mL}$ distilled water, and the mixture was filtered. The $\mathrm{pH}$ of the filtrate was measured using a $\mathrm{pH}$ meter (Adwa, AD1030 $\mathrm{pH} / \mathrm{mv}$ temperature meter).

2.2.7. Water Holding Capacity. Water holding capacities (WHCs) of chicken nugget samples were measured by centrifugation assay according to [23]. The samples were cut into cubes $50 \mathrm{mg}$ and then centrifuged at $1000 \times \mathrm{g}$ at $4^{\circ} \mathrm{C}$ for $15 \mathrm{~min}$, and WHC was calculated using the following formula:

$$
\mathrm{WHC}(\%)=\left(\frac{\text { weight before centrifugation }}{\text { weight after centrifugation }}\right) \times 100 \text {. }
$$

2.2.8. Microbiological Analysis of Chicken Nuggets. The microbial analysis was carried out according to [17, 24, 25]. Chicken nugget sample $(10 \mathrm{~g})$ was placed in a sterile test tube containing $90 \mathrm{~mL}$ of sterilized peptone water $(0.1 \%)$. The contents were homogenized at $14000 \times \mathrm{g}$ for $2.5 \mathrm{~min}$ and allowed to stand for about 6 minutes at room temperature. After that, a serial dilution was prepared $(1 \mathrm{~mL}$ aliquots from $10^{-1}$ to $10^{-6}$ dilutions). One $\mathrm{ml}$ from each of the previously prepared serial dilutions was aseptically transferred into duplicate plate count agar and incubated at $37^{\circ} \mathrm{C}$ for 48 hours. Violet red bile agar medium was used for Enterobacteriaceae bacteria. Only plates containing 30-300 colonies were counted and recorded as a total aerobic bacterial count cfu/g. The same methodology was used for total coliforms count [26] and total yeast and molds count [27] using Violet Red Bile agar medium (VRB) (Conda, Spain) and Potato dextrose agar (PDA) medium (Conda, Spain), respectively, and incubated at $28^{\circ} \mathrm{C}$ for $72 \mathrm{~h}$ for yeast and 5 days for mold.

2.2.9. Sensory Analysis. Sensory evaluation of chicken nuggets was executed immediately after processing to ensure that there are no negative impacts on the organoleptic properties of the developed product. Twenty experienced panelists from both genders in the age range from 30 to 45 years (10 males and 10 females) were chosen from the staff members of the Food Technology Department, Arid Lands Cultivation Research Institute, City of Scientific Research and Technological Applications, Alexandria, Egypt. They received a preparatory session related to the descriptive profile of sensory attributes (appearance, flavor, taste, color, tenderness, and overall acceptability). The panelists were not informed about the experimental approach, and the samples were blind-coded with specific random numbers. Every coded sample evaluated separately by each panelist and the panelists scored the sensory attributes such as appearance, flavor, taste, color, tenderness, and overall acceptability by nine-point hedonic scale ( 9 denotes extremely like and 1 denotes extremely dislike) [28].

2.2.10. Statistical Analysis. The received data were analyzed using one-way analysis of variance (ANOVA) with Duncan by SPSS ${ }^{\circledR}$ version 16.0. A statistical probability ( $p$ value) less than 0.05 indicated a statistically significant difference between groups [29]. 


\section{Results and Discussion}

3.1. A Proximate Chemical Analysis of Minced Chicken Meat. The analysis of chemical composition of macronutrients in minced chicken meat has emphasized that the chicken minced meat contains $74.26 \pm 0.61 \%$ moisture, $21.59 \%$ protein, $2.12 \%$ fat, and $2.03 \%$ ash which is meeting the Egyptian Standards [19] for meat and poultry products. The obtained data of the current analysis are in line with the data previously obtained by the authors of $[8,14]$.

3.2. Lipid Oxidation. During the 24 days of cold storage period at $4^{\circ} \mathrm{C}$ of processed chicken nugget samples, TBARS assay was used as an indicator of lipid oxidation. Permissible limit should not exceed $0.9 \mathrm{mg} \mathrm{MDA} / \mathrm{kg}$ sample according to Egyptian Standards [19] for meat and poultry products, the limit for TBARS (MDA equivalent) has been reported to be at $0.5 \mathrm{mg} / \mathrm{kg}$ of meat for the threshold of consumer detection of rancid flavor [30]. As presented in Figure 1, in the present study, at the beginning of the experiment (zero day) there was no significant difference was remarkable in TBARS values between the different nugget's samples $(p<0.05)$. On the other hand, through the 24 days of storage, the TBARS values increased significantly $(p<0.05)$ in the negative and positive control samples where the TBARS values elevated from 0.24 and $0.23 \mathrm{mg} \mathrm{MDA} / \mathrm{kg}$ at zero day to 2.39 and $2.00 \mathrm{mg} \mathrm{MDA} / \mathrm{kg}$, respectively, at 24 days of cold storage. While in quinoa-coated nuggets, the TBARS values increased from $0.18 \mathrm{mg} \mathrm{MDA} / \mathrm{kg}$ at zero day to $1.07 \mathrm{mg} \mathrm{MDA} /$ $\mathrm{kg}$ at 24 days of cold storage (Figure 1). The negative control group had exceeded the permissible limits at 12 days of storage with TBARS value of $0.95 \mathrm{mg} \mathrm{MDA} / \mathrm{kg}$ and became unfit compared with the quinoa-coated chicken nuggets group which did not change significantly at 24 days of cold storage $(0.35 \mathrm{mg} \mathrm{MDA} / \mathrm{kg})$. Furthermore, the inhibition of lipid oxidation by the effect of quinoa flour was remarked till 18 days of cold storage $(0.46 \mathrm{mg} \mathrm{MDA} / \mathrm{kg})$ compared to negative control $(1.26 \mathrm{mg} \mathrm{MDA} / \mathrm{kg})$ and positive control (BHT) (1.13 mg MDA/kg) samples. It should be noted here that the antioxidant effect of quinoa flour at freezing storage conditions $\left(-20^{\circ} \mathrm{C}\right)$ will be much more effective and the storage period will be much more extended. This might be due to the high antioxidant properties of quinoa flour [14, 17]. The retardation of lipid oxidation might be mainly caused by the radical scavenging activity, lipoxygenase inhibitory action, and metal chelating activity of phenolic compounds.

3.3. Protein Oxidation. Protein oxidation level at cold storage $\left(4 \pm 1^{\circ} \mathrm{C}\right)$ was evaluated by DNPH assay. The levels of $\mathrm{DNPH}$ during 24 days of cold storage $\left(4 \pm 1^{\circ} \mathrm{C}\right)$ are presented in Figure 2. The carbonyl content was increased significantly $(p<0.05)$ in the negative $(\mathrm{NC})$ and positive control (PC) samples during the 24 days of cold storage. The carbonyl content in the negative control was elevated from $0.60 \mathrm{nmol} / \mathrm{mg}$ protein at zero day to $6.44 \mathrm{nmol} / \mathrm{mg}$ protein at $24^{\text {th }}$ day of storage, while the carbonyl content value was increased from $0.59 \mathrm{nmol} / \mathrm{mg}$ protein at zero day to 5.93 at

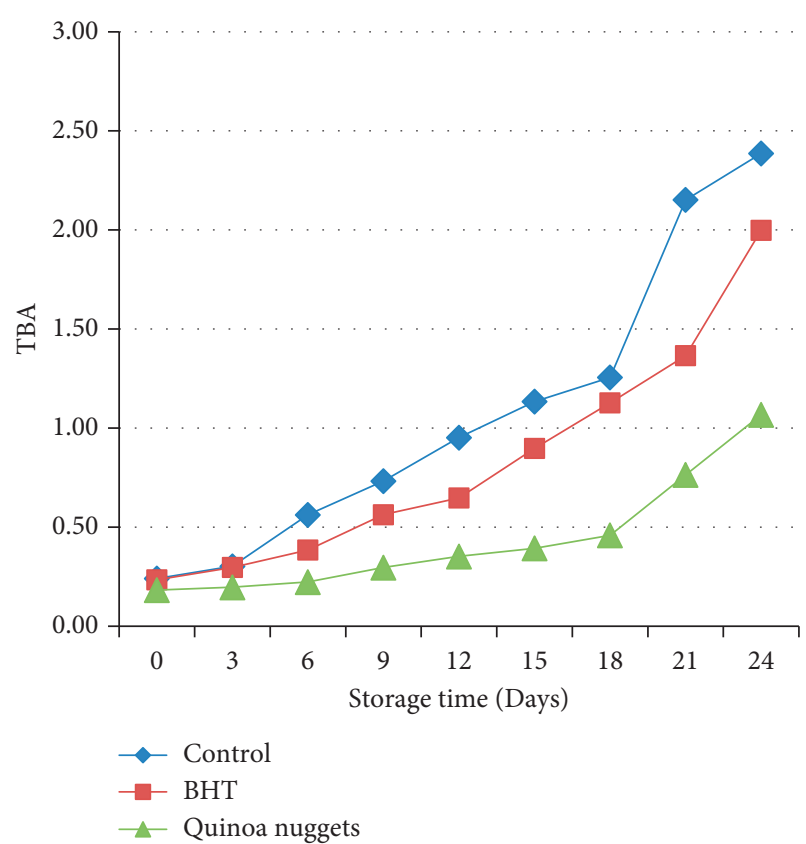

FIgURE 1: Lipid oxidation (TBARS) (mg MDA $/ \mathrm{kg}$ ) of chicken nugget samples during storage at $4^{\circ} \mathrm{C}$ for 24 days.

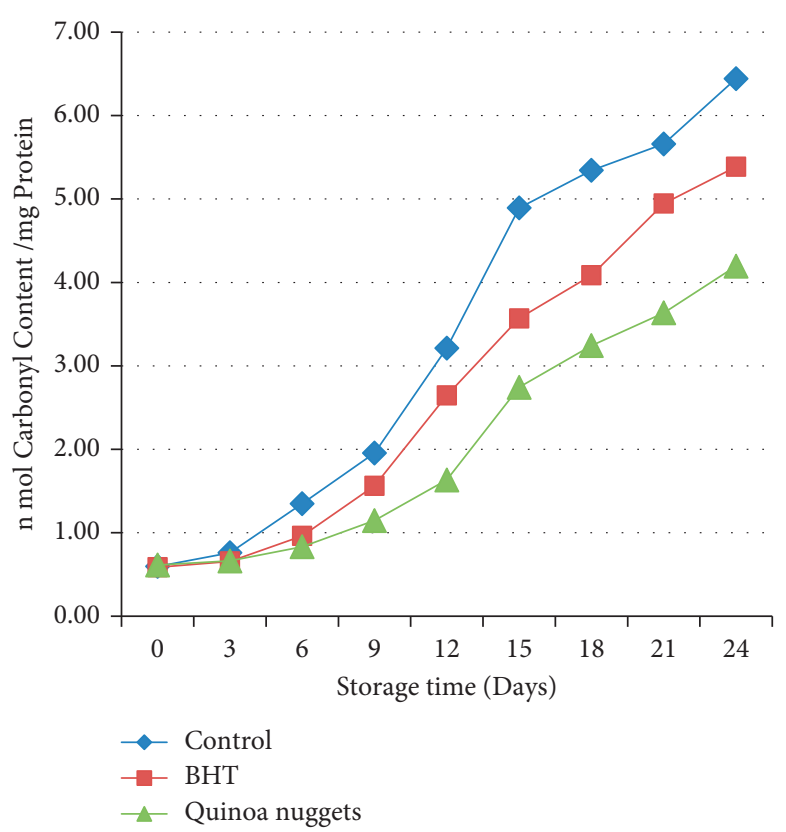

Figure 2: Protein oxidation (DNBH) (nmol carbonyl content/mg protein) of chicken nugget samples during storage at $4^{\circ} \mathrm{C}$ for 24 days.

$24^{\text {th }}$ day of storage for a positive control (BHT). On the other hand, chicken nuggets battered and baked with quinoa flour showed a mild increase in carbonyl content from $0.61 \mathrm{nmol} / \mathrm{mg}$ protein at zero day to $4.20 \mathrm{nmol} / \mathrm{mg}$ protein at day $24^{\text {th }}$ of storage which is significantly lower than the negative and positive control $(p<0.05)$. This is due to the high antioxidant activity of quinoa flour which was studied by [14]. Protein oxidation may cause an alteration in the physicochemical properties of proteins such as 
structure, solubility, and proteolysis, affecting the quality of meat products. Furthermore, the increasing of protein oxidation levels in meat products may cause various implications on the consumers' health [31]. The potent of quinoa flour in the retarding of protein oxidation in chicken nuggets $(\mathrm{QN})$ in the present study leads to a limit of the health risk of carbonyl content, which emphasizes the usefulness of the utilizing of quinoa flour in various processed meat products such as chicken nuggets, burger, and fish fingers.

3.4. $p H$ Value. The effect of quinoa flour on the $\mathrm{pH}$ values of chicken nugget samples during storage time at $4^{\circ} \mathrm{C}$ is presented in Figure 3. The $\mathrm{pH}$ value of negative control (NC) was found to be $6.64 \pm 0.01$, while the $\mathrm{pH}$ value of positive control (PC) was found to be $6.64 \pm 0.01$ and the $\mathrm{pH}$ value for quinoa-coated chicken nuggets $(\mathrm{QN})$ was $6.95 \pm 0.03$ at zero time with no significant different $(p>0.05)$. The $\mathrm{pH}$ value of all samples was gradually decreased with the increasing of storage time. At the $24^{\text {th }}$ day of storage, there was significant difference found between all chicken nugget samples which reached final $\mathrm{pH}$ values of $4.39 \pm 0.01$ for negative control (NC) and $4.97 \pm 0.02$ for positive control (PC), while the $\mathrm{pH}$ value of quinoa-coated nuggets $(\mathrm{QN})$ was $5.71 \pm 0.01$. The $\mathrm{pH}$ values were significantly reduced in both negative and positive control in comparison with the chicken nuggets coated with quinoa flour $(p<0.05)$ (Figure 3). The deceasing of $\mathrm{pH}$ value in the quinoa flourcoated chicken nuggets $(\mathrm{QN})$ was observed but not lower than other samples, which is indicating the antimicrobial efficacy of quinoa flour somewhat reduces the growth of acid producing bacteria (LAB) leads to lightly preventing the sharp lowering of the $\mathrm{pH}$ levels. In general, the decreasing of $\mathrm{pH}$ values in all samples about 2 units is resulting in the growth of lactic acid bacteria (LAB) which producing lactic acid in the product. These findings are in agreement with the result presented by [32] who revealed the antimicrobial and antioxidant effect of quinoa flour. This finding would be playing a key role in the extension of the shelf life of the chicken nuggets by coating them with quinoa flour.

3.5. Water Holding Capacity (WHC). Water holding capacity (WHC) of chicken nugget samples during storage is presented in Figure 4. There was no significant difference $(p>0.05)$ in WHC between the nugget samples at zero day, while through the 24 days of storage, the WHC decreased significantly in the negative and positive control. The WHC of negative control was decreased from 93.28 to $86.94 \%$, and the positive control was changed from 93.45 to $89.46 \%$ during 24 days of cold storage. On the other hand, the chicken nuggets coated with quinoa flour showed the lowest decrease of WHC during 24 days of cold storage (from 95.49 to $91.26 \%$ ). The water holding capacity of chicken nuggets is a functional property of quinoa flower to increase the water holding capacity of any product [32]. The coating of chicken nuggets with quinoa flour increases the water retention during the storage period which is useful to retain the freshness of the product. The increase of water holding capacity in quinoa-coated chicken nuggets $(\mathrm{QN})$ may be due

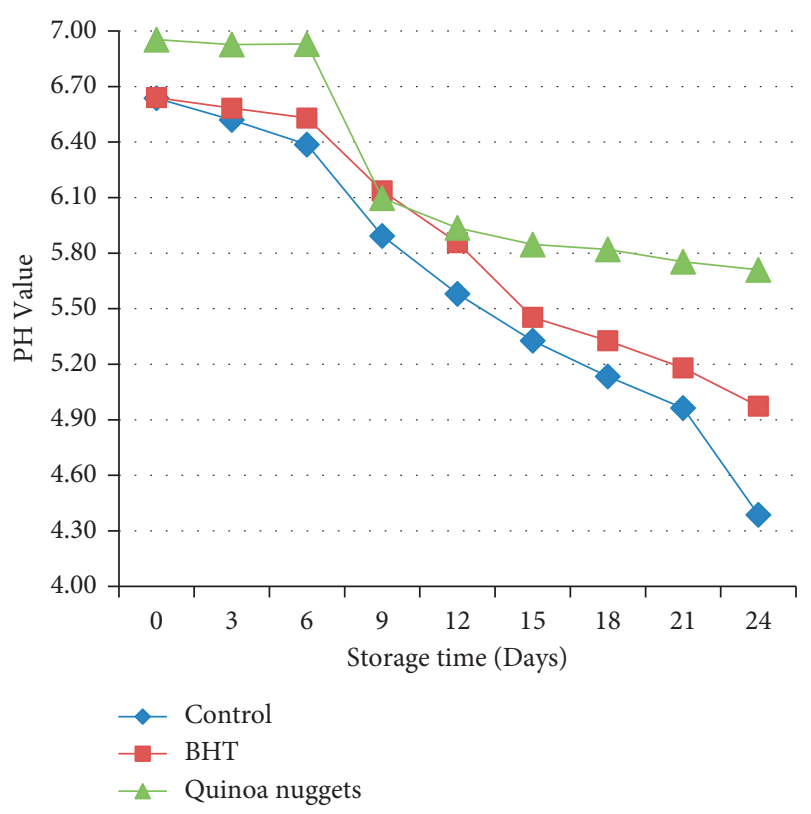

FIGURE 3: $\mathrm{pH}$ values of chicken nugget samples during storage at $4^{\circ} \mathrm{C}$ for 24 days.

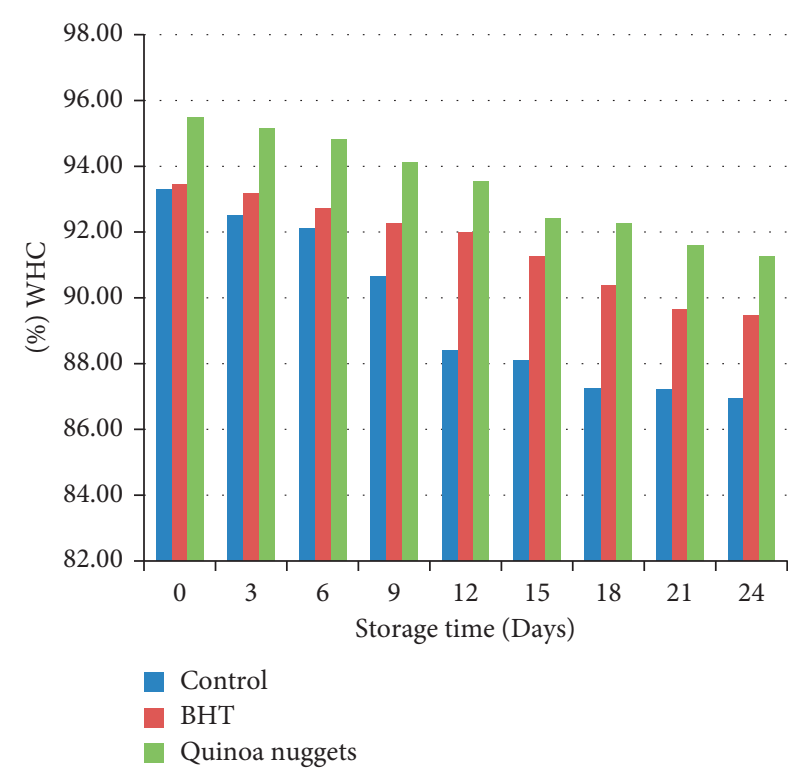

Figure 4: Water holding capacity (WHC) of chicken nugget samples during storage at $4^{\circ} \mathrm{C}$ for 24 days.

to the limit of oxidation of protein which has the ability for water holding capacity and the presence of quinoa flour as well. There was a clear tendency for WHC to increase with increasing $\mathrm{pH}$ values due to the increase in solubility of meat proteins that move away from the isoelectric point. So, in the current study, the WHC was increased, while $\mathrm{pH}$ values were decreased which is reflected the ability of quinoa flour for protecting the protein and retention of water with low $\mathrm{pH}$.

3.6. Total Bacterial Count ( $c f u / g$ ). Results presented in Figure 5 showed the effect of coating chicken nuggets with quinoa flour on the total bacterial count during the 24 


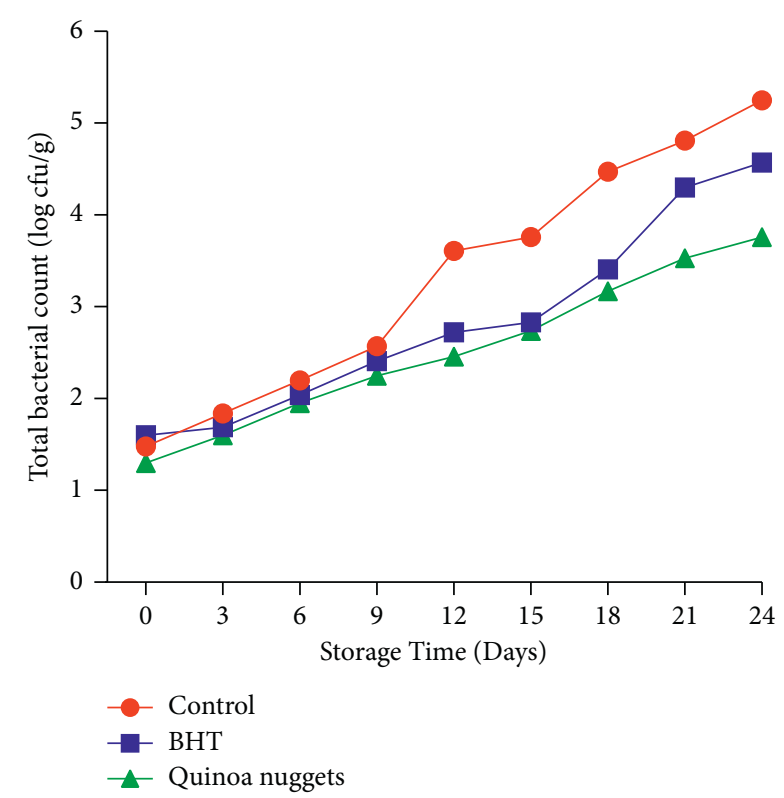

FIgURE 5: Total bacterial count $(\log \mathrm{cfu} / \mathrm{g})$ of chicken nugget samples during storage at $4^{\circ} \mathrm{C}$ for 24 days.

days of cold storage at $4 \pm 2{ }^{\circ} \mathrm{C}$. Total bacterial count is expressed as (cfu/g) colony forming unit/gram of sample. At zero day, there was no significant difference $(p>0.05)$ in bacterial count between the different nugget's samples, while through the 24 days of cold storage, the bacterial count increased significantly $(p<0.05)$ with increasing the storage time. In the negative (NC) and positive control (PC) samples, the total bacterial count elevated from 1.477 and $1.60 \log \mathrm{cfu} / \mathrm{g}$ at zero day to 5.25 and $4.57 \log \mathrm{cfu} / \mathrm{g}$, respectively, at $24^{\text {th }}$ day of cold storage. By contrast, quinoa-coated chicken nuggets $(\mathrm{QN})$ samples showed the lowest increase in total bacterial count compared to negative and positive control, starting with $1.30 \mathrm{log} \mathrm{cfu} / \mathrm{g}$ at zero day to reach $3.76 \log \mathrm{cfu} / \mathrm{g}$ at the 24 th day of cold storage. From the obtained results in the present study, the utilizing of quinoa flour significantly prevented the increasing in the total bacterial count of chicken nuggets $(p<0.05)$ and maintained it below the permissible limit (did not exceed $10^{5} \mathrm{cfu} / \mathrm{g}$ ) (Egyptian Standards for meat poultry products, [19]). On the other hand, the permissible limit of the total bacterial count has been exceeded the permissible limit in the positive and negative control after 24 days of cold storage. The significant lowering of bacterial count during storage of quinoa-coated chicken nuggets might refer to the antimicrobial properties of quinoa flour by the ability of bioactive compounds to interact with cytoplasmic membrane of the bacteria and consequently limiting the ability of cell division $[14,33]$.

3.7. Coliform Count ( $c f u / g$ ). Results presented in Figure 6 showed the coliform count in nugget samples during the 24 days of cold storage at $4^{\circ} \mathrm{C}$ expressed as (log cfu/g). Through the 24 days of storage, the coliform count increased significantly in the negative (NC) and positive (PC) control where the coliform count elevated from 1.30 and $1.47 \mathrm{log}$

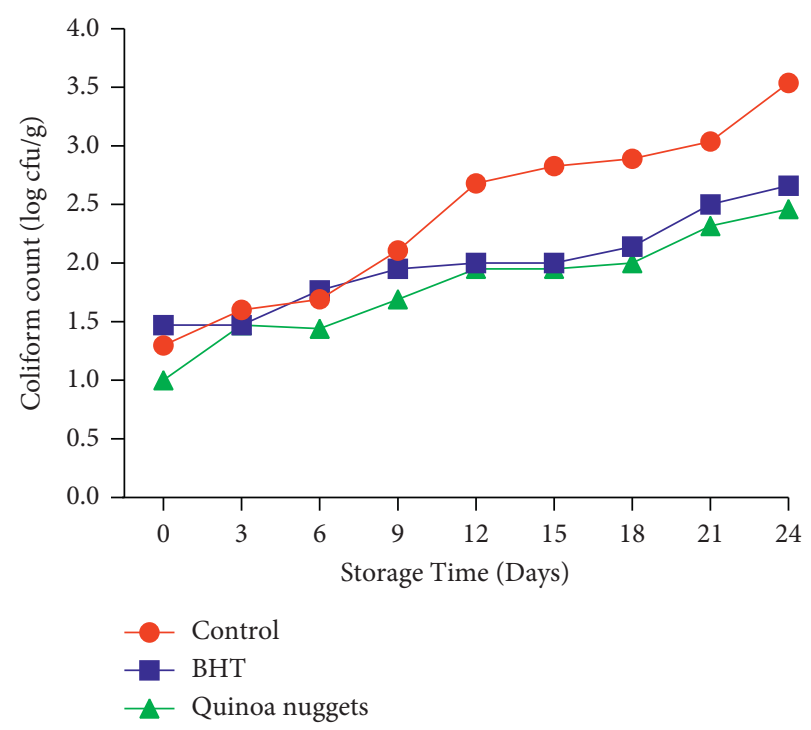

FIgUre 6: Coliform count (log cfu/g) of chicken nugget samples during storage at $4^{\circ} \mathrm{C}$ for 24 days. - permissible limit should not exceed $10^{2} \mathrm{cfu} / \mathrm{g}$ according to Egyptian Standards [19] for meat poultry products.

$\mathrm{cfu} / \mathrm{g}$, respectively, at zero day to $1.95 \mathrm{log} \mathrm{cfu} / \mathrm{g}$ for the negative control and $1.69 \mathrm{log} \mathrm{cfu} / \mathrm{g}$ for the positive control group at the $9^{\text {th }}$ day of cold storage which have exceeded the permissible limits $\left(10^{2} \mathrm{cfu} / \mathrm{g}\right)$ according to Egyptian Standards [19] for meat poultry products. On the contrary, quinoa-coated nuggets (QN) showed the lowest coliform count compared to negative and positive controls, where the coliform count at the zero day was $1 \log \mathrm{cfu} / \mathrm{g}$ and reached $2 \log \mathrm{cfu} / \mathrm{g}$ at $18^{\text {th }}$ day of cold storage which still agree with a permissible limit. These results agreed with $[33,34]$ who reported the antimicrobial effect of coating with quinoa flour. The antibacterial activity of quinoa flour preventing the different bacterial growth in the quinoa-coated nuggets might be due to its phenolic and flavonoids content and residue of saponin content which considered a strong antibacterial. The obtained results revealed that the utilizing of quinoa flour for coating the chicken nuggets was prolonged the shelf life of the product up to the 18th day compared to the negative and positive control, which reached just 9 days (2-fold increase).

3.8. Total Yeast and Mold Count (cfu/g). Results presented in Table 2 showed the total yeast and mold count in nugget samples during the 24 days of cold storage at $4 \pm^{\circ} \mathrm{C}$. There was no yeast or mold count detected in all nugget samples at zero day, while through the 24 days of storage, the count of mold and yeast was increased significantly $(p<0.05)$ to reach a permissible limit at the day 15 for negative control (NC), day 21 for positive control (PC), and day 24 for quinoa-coated nuggets (sample should be free from visible fungal growth according to Egyptian Standards [19] for meat poultry products). In the negative control (NC) group, the count of mold and yeast showed a result of $1.69 \log \mathrm{cfu} / \mathrm{g}$ at the day 15 , the positive control (PC) (BHT) group showed the count of $1.60 \log \mathrm{cfu} / \mathrm{g}$ at the day 21 of storage but no mold and yeast 
TAвLE 2: Total yeast and mold count (log cfu/g) of chicken nugget samples during storage at $4^{\circ} \mathrm{C}$ for 24 days.

\begin{tabular}{lccc}
\hline Storage time (days) & Control & BHT & Quinoa nuggets \\
\hline 0 & ND & ND & ND \\
3 & ND & ND & ND \\
6 & ND & ND & ND \\
9 & ND & ND & ND \\
12 & ND & ND & ND \\
15 & 1.69 & ND & ND \\
18 & 1.90 & ND & ND \\
21 & 2.07 & 1.60 & ND \\
24 & 2.39 & 1.84 & 1.47 \\
\hline
\end{tabular}

Products should be free from visible fungal growth according to Egyptian standards [19] for meat poultry products.

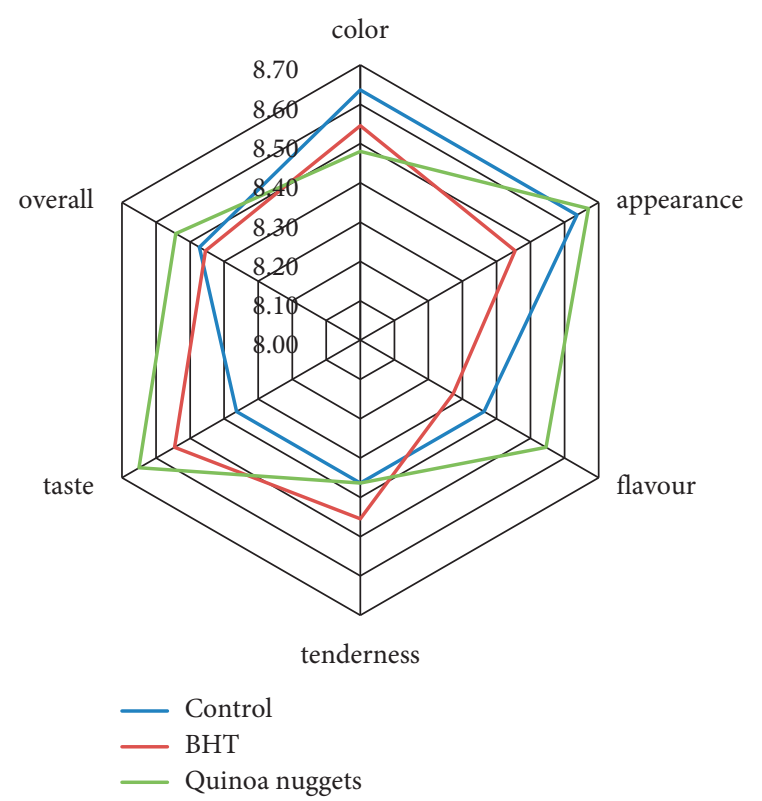

Figure 7: The sensory scores of chicken nuggets.

cells were detected at the day 21 in quinoa-coated nugget samples. The count of mold and yeast were detected at the day 24 with the count of $1.47 \mathrm{log} \mathrm{cfu} / \mathrm{g}$. It is well established that yeasts and molds form the most common microbial deterioration of chicken meat during cold storage conditions [35]. These results agreed with [33, 34] who studied the antimicrobial effect of coating with quinoa flour. In the present study, it can be stated that quinoa flour has the ability to retard the deterioration of chicken nuggets resulting to extend its shelf life. The retardation of the deterioration of chicken nuggets might be due to the effect of the phenolic contents and other bioactive compounds in quinoa flour.

3.9. Sensory Evaluation. The sensory attributes of nugget samples are presented in Figure 7. The sensory evaluation showed that there are no significant differences between quinoa-coated chicken nuggets and positive and negative control samples $(p<0.05)$ in all sensory criteria including appearance, taste, color, flavor, and overall acceptability after processing. On the other hand, there was a significant difference in the overall acceptability which indicated that the panelists are preferred the quinoa-coated chicken nuggets (Figure 7). Sensory evaluation of chicken nuggets revealed that the substitution of wheat flour with quinoa flour in coating chicken nuggets did not significantly affect their organoleptic properties and the acceptability of the consumers (Figure 5). These results agree with [36] who reported that the addition of quinoa flour to meat nuggets resulting in no significant negative change in sensory characteristics.

\section{Conclusion}

The present work was focused on the development of innovative quinoa-coated chicken nuggets for celiac patients. Furthermore, asses the ability of quinoa flour to retard the lipid and protein oxidation and decrease the microbiota in the developed product. Quinoa flour effectively retarded the oxidation of lipid and protein content in the developed quinoa-coated nuggets. The utilizing of quinoa flour delayed the lipid oxidation in developed products to maintain it below the standard limit $(0.46 \mathrm{mg} \mathrm{MDA} / \mathrm{kg})$ up to 18 days of cold storage compared to negative control $(1.26 \mathrm{mg} \mathrm{MDA} / \mathrm{kg})$ and positive control (BHT) (1.13 mg MDA/kg) samples which exceeded the permissible limit during the same storage period. At the same time, innovative chicken nuggets battered and baked with quinoa flour retarded the formation of carbonyl content which is reached $4.20 \mathrm{nmol} / \mathrm{mg}$ protein at day $24^{\text {th }}$ of cold storage $(p>0.05)$. Furthermore, quinoa flour prevented a microbial deterioration and improved water holding capacity and the organoleptic traits, resulting in an extension of its shelf life during cold storage at $4 \pm 1^{\circ} \mathrm{C}$ with results superior to synthetic preservatives (BHT) and wheat flour. The obtained results of the current study may open a promising perspective for continuing more intensive research for utilization of quinoa flour for developing a gluten-free nugget for people suffering from celiac problems. At the same time, quinoa flour might be beneficial for extending the shelf life of various processed meat products due to its antioxidant and antimicrobial potential.

\section{Data Availability}

The supporting data are available from the corresponding author upon request.

\section{Conflicts of Interest}

The authors declare no conflicts of interest. 


\section{Acknowledgments}

The authors deeply appreciate the valuable support provided by Food Technology Dept., Arid Lands Cultivation Research Institute (ALCRI), City of Scientific Research and Technological Applications (SRTA-City), Alexandria, Egypt, to achieve this work.

\section{References}

[1] J. Stangierski and G. Lesnierowski, "Nutritional and healthpromoting aspects of poultry meat and its processed products," World's Poultry Science Journal, vol. 71, no. 1, pp. 71-82, 2015.

[2] S. Xiao, W. G. Zhang, E. J. Lee, C. W. Ma, and D. U. Ahn, "Lipid and protein oxidation of chicken breast rolls as affected by dietary oxidation levels and packaging," Journal of Food Science, vol. 76, pp. C612-C617, 2011.

[3] M. Du and D. U. Ahn, "Effect of antioxidants on the quality of irradiated sausages prepared with Turkey thigh meat," Poultry Science, vol. 81, pp. 1251-1256, 2002.

[4] S. F. Dogan, S. Sahin, and G. Sumnu, "Effects of soy and rice flour addition on batter rheology and quality of deep-fat fried chicken nuggets," Journal of Food Engineering, vol. 71, pp. 127-132, 2005.

[5] M. Tamsen, H. Shekarchizadeh, and N. Soltanizadeh, "Evaluation of wheat flour substitution with amaranth flour on chicken nugget properties," LWT, vol. 91, pp. 580-587, 2018.

[6] I. Gulcin, Z. Huyut, M. Elmastas, and H. Y. Aboul-Enein, "Radical scavenging and antioxidant activity of tannic acid," Arabian Journal of Chemistry, vol. 3, pp. 43-53, 2010.

[7] M. Wahab, S. Sohaimy, H. Ibrahim, and H. Makarem, "Effect of natural antioxidant extracts on oxidative and microbiological stability of beef burger," Alexandria Journal of Veterinary Sciences, vol. 60, no. 1, pp. 141-154, 2019.

[8] M. Jouki and N. Khazaei, "Effects of active batter coatings enriched by quince seed gum and carvacrol microcapsules on oil uptake and quality loss of nugget during frying," Journal of Food Science \& Technology, vol. 2021, pp. 1-10, 2021.

[9] J. Mohammad, M. Rabbani, and S. M. Javad, "Effects of pectin and tomato paste as a natural antioxidant on inhibition of lipid oxidation and production of functional chicken breast sausage," Food Science and Technology, vol. 40, no. S2, pp. 521-527, 2020.

[10] M. Jouki, M. Rabbani, M. J. Shakouri, and N. Khazaei, "Effects of deep-fat frying and active pretreatments of tomato pectin and paste on physical, textural and nutritional properties of fried frankfurter-type chicken sausage," Journal of Food Measurement and Characterization, vol. 15, pp. 5485-5494, 2021.

[11] S. A. El-Sohaimy, S. E. Mohamed, M. G. Shehata, M. Taha, and M. A. Zaitoun, "Compositional analysis and functional characteristics of quinoa flour," Annual Research \& Review in Biology, vol. 22, no. 1, pp. 1-11, Article ID ARRB.38435, 2018.

[12] S. A. El-Sohaimy, T. M. Refaay, and M. A. M. Zaytoun, "Physicochemical and functional properties of quinoa protein isolate," Annals of Agricultural Science, vol. 60, no. 2, pp. 297-305, 2015.

[13] S. A. El-Sohaimy, M. G. Shehata, T. Mehany, and M. A. Zeitoun, "Nutritional, physicochemical, and sensorial evaluation of flat bread supplemented with quinoa flour," International journal of Food Science, vol. 2019, Article ID 4686727, 15 pages, 2019.
[14] J. H. Park, Y. J. Lee, Y. H. Kim, and K. S. Yoon, “Antioxidant and antimicrobial activities of quinoa (chenopodium quinoa willd.) seeds cultivated in Korea," Preventive Nutrition and Food Science, vol. 22, no. 3, pp. 195-202, 2017.

[15] S. M. Hosseini, S. Nafiseh, M. Parisa, B. Parisa, M. Leila, and S.-A. Saeedeh, "Gluten-free products in celiac disease: nutritional and technological challenges and solutions," Journal of Research in Medical Sciences, vol. 28, no. 23, p. 109, 2019.

[16] C. Carolina, C. Paul, M. Hadjivassiliou, K. Kaukinen et al., The gluten-free diet and its current application in coeliac disease and dermatitis herpetiformis," United European Gastroenterology Journal, vol. 3, no. 2, pp. 121-135, 2015.

[17] E.-S. S. Ahmed, M. G. Shehata, H. S. Abd-Rabou, and H. ElMenshawy, "Extend shelf-life of vacuum-packaged herring fish fillets using garlic and ginger extracts," Journal of Pure and Applied Microbiology, vol. 13, no. 3, pp. 1571-1581, 2019.

[18] Association of Official Analytical Chemists-AOAC, "Official methods of analysis," in Chemical Analysis of Chicken Meat with Relation to Its Quality, W. Horwitz, Ed., Academic Press, Washington, DC, USA, 13th edition, 2000.

[19] Egyptian Organization for Standardization and Quality Control, "For meat poultry products," 2005, https://www.eos. org.eg/en/page/24.

[20] K. Radha krishnan, S. Babuskin, P. Azhagu Saravana Babu et al., "Antimicrobial and antioxidant effects of spice extracts on the shelf-life extension of raw chicken meat," International Journal of Food Microbiology, vol. 171, pp. 32-40, 2014.

[21] R. L. Levine, D. Garland, C. N. Oliver et al., "Determination of carbonyl content in oxidatively modified proteins," Methods in Enzymology, vol. 186, pp. 464-478, 1990.

[22] M.-J. Lemay, J. Choquette, P. J. Delaquis, C. Gariépy, N. Rodrigue, and L. Saucier, "Antimicrobial effect of natural preservatives in a cooked and acidified chicken meat model," International Journal of Food Microbiology, vol. 78, pp. 217226, 2002.

[23] M. Mehri, V. Sabaghi, and F. Bagherzadeh-Kasmani, "Mentha piperita (peppermint) in growing Japanese quail diet: serum biochemistry, meat quality, humoral immunity," Animal Feed Science and Technology, vol. 206, pp. 57-66, 2015.

[24] American Public Health Association (Apha), Compendium of Methods for the Microbiological Examination of Foods, A.P.H.A. Inc., Washington, DC, USA, 1992.

[25] M. Jouki, F. T. Yazdi, S. A. Mortazavi, A. Koocheki, and N. Khazaei, "Effect of quince seed mucilage edible films incorporated with oregano or thyme essential oil on shelf-life extension of refrigerated rainbow trout fillets," International Journal of Food Microbiology, vol. 174, pp. 88-97, 2014.

[26] ICMSF-International Commission on Microbiological Specification for Foods, "Microorganisms in foods," in Intestinally Pathogenic Escherichia coliBlackie Academic and Professional, London, UK, 1996.

[27] M. V. Copetti, J. M. Santurio, A. Cavalheiro, S. H. Alves, and L. Ferreiro, "Comparison of different culture media for mycological evaluation of commercial pet food," Acta Scientiae Veterinariae, vol. 37, no. 4, pp. 329-335, 2009.

[28] J. Fernández-López, S. Jiménez, E. Sayas-barberá, E. Sendra, and J. Pérez-Alvarez, "Quality characteristics of ostrich (Struthio camelus) burgers," Meat Science, vol. 73, pp. 295-303, 2006.

[29] R. G. Steel and J. H. Torrie, Principles and Procedures of Statistics, London: McGraw-Hill Book Company, Inc., London, UK, 1980.

[30] Y. S. Choi, J. H. Choi, D. J. Han et al., "Effects of replacing pork back fat with vegetable oils and rice bran fiber on the 
quality of reduced-fat frankfurters," Meat Science, vol. 84, no. 3, pp. 557-563, 2010.

[31] W. Zhang, S. Xiao, and D. U. Ahn, "Protein oxidation: basic principles and implications for meat quality," Critical Reviews in Food Science and Nutrition, vol. 53, no. 11, pp. 1191-1201, 2013.

[32] L. E. A. James, "Quinoa (chenopodium quinoa willd.): composition, chemistry, nutritional, and functional properties," Advances in Food and Nutrition Research, vol. 58, pp. 1-31, 2009.

[33] E. Medina, N. Caro, L. Abugoch, A. Gamboa, M. DíazDosque, and C. Tapia, "Chitosan thymol nanoparticles improve the antimicrobial effect and the water vapour barrier of chitosan-quinoa protein films," Journal of Food Engineering, vol. 240, pp. 191-198, 2019.

[34] C. H. Pagno, T. V. Klug, T. M. H. Costa, A. de Oliveira Rios, and S. H. Flôres, "Physical and antimicrobial properties of quinoa flour-based films incorporated with essential oil," Journal of Applied Polymer Science, vol. 133, no. 16, pp. 1-9, 2016.

[35] J. M. Jay, M. J. Loessner, Golden, and A. David, Modern Food Microbiology, Springer Science Inc, New York, NY, USA, 7th edition, 2005.

[36] A. K. Verma, V. Rajkumar, and S. Kumar, "Effect of amaranth and quinoa seed flour on rheological and physicochemical properties of goat meat nuggets," Journal of Food Science and Technology, vol. 56, no. 11, pp. 5027-5035, 2019. 